\title{
Self-organized templates provide backbone for all integrated Li-ion batteries
}

\author{
Kiyoung Lee and Patrik Schmuki \\ NPG Asia Materials (2015) 7, e185; doi:10.1038/am.2015.44; published online 5 June 2015
}

Batteries as well as modern supercapacitors involve a surface redox reaction and an ion intercalation process on anodes and cathodes. For an optimum electrode performance, a broad range of ion intercalation materials in nanoscale morphologies is currently being investigated. The nanoscale assembly of electrodes is not only crucial to maximize the specific surface area (volumetric charging capacity with ions or electrons) and to efficiently use an optimized ion interaction thickness (solid state diffusion of the intercalating species of a few $\mathrm{nm}$ ). However, classic geometries involving two nanostructured electrodes (such as in Figure 1a) arranged either in a parallel or interdigitated configuration have limitations in view of an efficient intercalation reaction, especially at high charging/discharging rate due to (diffusion limited) $\mathrm{Li}$ ion depletion within the nanostructures or an irregular charge distribution along the nanostructure scaffold. ${ }^{1-3}$

The recent work by Rubloff et al. ${ }^{4}$ suggests another highly original, yet strikingly simple concept to tackle these issues. The authors directly fabricate a full-cell Li-ion battery by depositing anode and cathode into pores of self-organized alumina oxide (Figure 1b) based on a set of entirely self-ordering construction steps.

As substrate for the battery serves a selforganized porous alumina template that inherently provides a number of geometrical optimization features (length and diameter of pores)—but moreover the partial filling of the tubes with the $\mathrm{Ru} / \mathrm{V}_{2} \mathrm{O}_{5}$ electrode materials seems to be adjustable simply by the penetration depth of the atomic layer deposition (ALD) process of the respective materials.

In the present concept, a conformal ALD wall cladding of $\mathrm{Ru} /$ crystalline $\alpha-\mathrm{V}_{2} \mathrm{O}_{5}$ is used as an anode and $\mathrm{Ru}$ /prelithiated $\mathrm{V}_{2} \mathrm{O}_{5}\left(\mathrm{Li}_{\mathrm{x}} \mathrm{V}_{2} \mathrm{O}_{5}\right)$ is used a

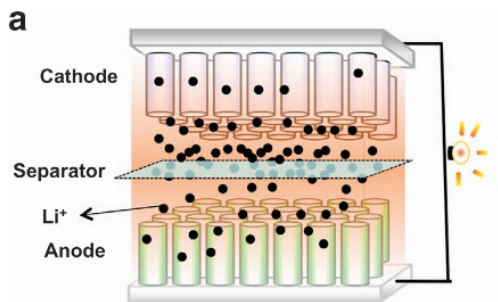

b

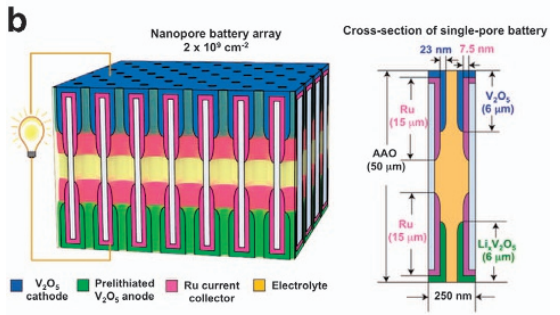

Figure 1 Schematic of (a) classic nanostructured $\mathrm{Li}$ ion battery and (b) newly designed all-in-one Li ion battery, with permission from Macmillan Publishers.

as a cathode ( $\mathrm{Ru}$ metal is considered to act as a current collector).

Except for the simplicity of the concept, the most beneficial effect of the configuration is the fully contacted electrolyte on each electrode, a short $\mathrm{Li}$ ion diffusion length and a high ionic conductivity that combined lead to a high specific capacity. ${ }^{5}$

From a fundamental scientific viewpoint, it is worth noting that the work reaches extremely interesting electrochemical dimensions where classic intercalation (battery) and classic surface charging (supercapacitors) begin to unify.
At present, the absolute performance of this new one-dimensional design has not yet reached the level of commercial battery devices; nevertheless, there is sufficient room for optimization to make this concept a cornerstone for future generation of thin-film energy storage devices.

1 Rueno, P. R \& Leite, E. R. Nanostructured Li ion insertion electrodes. 1. Discussion on fast transport and short path for ion diffusion. J. Phys. Chem. B 107, 8688-8877 (2003).

2 Lee, K., Mazare, A. \& Schmuki, P. One-dimensional titanium dioxide nanomaterials: nanotubes. Chem. Rev. 114, 9385-9454 (2014).

3 Gowda, S. R., Reddy, A. L. M. Zhang, X. \& Ajayan, P. M. Building energy storage device on a single nanowire. Nano Lett. 11, 3329-3333 (2011).

4 Liu, C., Gillette, E. I., Chen, X., Pearse, A. J., Kozen, A. C., Schroeder, M.A., Gregorczyk, K. E., Lee, S. B. \& Rubloff, G. W. An all-in-one nanopore battery array. Nat. Nanotechnol. 9, 1031-1039 (2014).

5 Rhodes, C. P., Long, J. W., Doescher, M. S., Fontanella, J. J. \& Rolison, D. R. Nanoscale polymer electrolytes: ultrathin electrodeposited poly(phenylene oxide) with solid-state ionic conductivity. J. Phys. Chem. B 108, 13079-13087 (2004).

(c) (i)

This work is licensed under a Creative Commons Attribution 4.0 International License. The images or other third party material in this article are included in the article's Creative Commons license, unless indicated otherwise in the credit line; if the material is not included under the Creative Commons license, users will need to obtain permission from the license holder to reproduce the material. To view a copy of this license, visit http:// creativecommons.org/licenses/by/4.0/ 